\title{
Mechanisms for European summer temperature response to solar forcing over the last millennium
}

\author{
D. Swingedouw ${ }^{1}$, L. Terray ${ }^{2}$, J. Servonnat ${ }^{1}$, and J. Guiot ${ }^{3}$ \\ ${ }^{1}$ Laboratoire des Sciences du Climat et de l'Environnement, IPSL-CEA-CNRS-UVSQ - UMR8212, \\ Centre d'Etudes de Saclay, Orme des Merisiers bat. 701, 91191 Gif Sur Yvette, France \\ ${ }^{2}$ CERFACS, 42 Av. G. Coriolis, 31057 Toulouse, France \\ ${ }^{3}$ CEREGE, Europôle Méditerranéen de l'Arbois - Avenue Louis Philibert, BP 80, 13545 Aix en Provence, France \\ Correspondence to: D. Swingedouw (didier.swingedouw@1sce.ipsl.fr) \\ Received: 28 March 2012 - Published in Clim. Past Discuss.: 18 April 2012 \\ Revised: 28 August 2012 - Accepted: 29 August 2012 - Published: 5 October 2012
}

\begin{abstract}
A simulation of the last millennium is compared to a recent spatio-temporal reconstruction of summer temperature over Europe. The focus is on the response to solar forcing over the pre-industrial era. Although the correlation between solar forcing and the reconstruction remains small, the spatial regression over solar forcing shows statistically significant regions. The meridional pattern of this regression is found to be similar in the model and in the reconstruction. This pattern exhibits a large warming over Northern and Mediterranean Europe and a lesser amplitude response over Central and Eastern Europe. The mechanisms explaining this pattern in the simulation are mainly related to evapotranspiration fluxes. It is shown that the evapotranspiration is larger in summer over Central and Eastern Europe when solar forcing increases, while it decreases over the Mediterranean area. The explanation for the evapotranspiration increase over Central and Eastern Europe is found in the increase of winter precipitation there, leading to a soil moisture increase in spring. As a consequence, the evapotranspiration is larger in summer, which leads to an increase in cloud cover over this region, reducing the surface shortwave flux there and leading to less warming. Over the Mediterranean area, the surface shortwave flux increases with solar forcing, the soil becomes dryer and the evapotranspiration is reduced in summer leading to a larger increase in temperature. This effect appears to be overestimated in the model as compared to the reconstruction. Finally, the warming of Northern Europe is related to the albedo feedback due to sea-ice cover retreat with increasing solar forcing.
\end{abstract}

\section{Introduction}

The projections of the coming century under increasing anthropogenic forcing show that one of the largest warming in summer is likely to occur in the Mediterranean area (Christensen et al., 2007). This is mainly related to a local feedback (Seneviratne et al., 2006) and to a change in the large-scale circulation with a northward shift in the jet stream and the subsidence regions (Yin, 2005), which may be larger with the increase in the vertical resolution of the atmosphere models and their representation of the stratosphere (Scaife et al. 2012). This leads to an anisotropic response of summer temperature over Europe to a change in radiative forcing even for an isotropic forcing.

The local positive feedback implies a land-atmosphere interaction: in relatively dry regions, an increase in surface temperature decreases the soil moisture reservoir so that the evapotranspiration is partly replaced by sensible heat flux that warms the soil in place of the cooling associated with the latent heat flux from evapotranspiration (Seneviratne et al., 2006; D'Andréa et al., 2006). Under global warming, this mechanism leads to the existence of a transitional zone over Europe, located between 40 and $60^{\circ} \mathrm{N}$, where the moisture availability allows to avoid the inception of the positive feedback (Boé and Terray, 2008). Nevertheless, there is a very large spread among the models concerning the location of this zone, illustrating the sensitivity of this mechanism to climate models parameterisation and the necessity to constrain them through observations. Evapotranspiration is actually the key variable that controls this transition zone. This 
is a complex flux that couples both the energy and water budget of the soil.

The uncertainty for the summer evapotranspiration response of models participating in IPCC-AR4 necessitates evaluating their sensitivity to change in radiative forcing for past periods over sufficiently long time scale. Using reconstruction of the last few decades is a possibility, but analysing longer time scale will certainly help to filter out the signature of internal climate variability. The last millennium, with well-documented variations in solar forcing (although uncertainties remain concerning its amplitude) appears to be an interesting candidate. Hunt (2006) actually shows that climate variability over this period could not be explained only by the internal variability of a climate model, but needs external forcing. Hegerl et al. (2011) confirm the importance of external forcing for the temperature variability over Europe for the last $500 \mathrm{yr}$. They also show that these forcings are mainly detectable in winter and less in summer, notably because dynamics are involved in winter and not only pure local radiative forcing. Moreover, they question the detectability of solar forcing in summer over this 500-yr time frame.

In this study we propose to evaluate the summer temperature response of a particular climate model to low frequency solar variations during the last millennium and compare it to a new reconstruction of summer temperature over Europe for this millennium time frame.

\section{Experimental design}

We analyse a simulation of the last millennium using the CNRM-CM3 coupled model (Salas-Mélia et al., 2005). This model is based on the coupled core formed by ARPEGE Climat version 4.6 AGCM (Gibelin and Déqué, 2003) and OPA 8.1 OGCM (Madec et al., 1998), including a sea-ice model, GELATO2 (Salas-Mélia, 2002). The horizontal resolution is around $2.8^{\circ}$ in the atmosphere and $2^{\circ}$ in the ocean (with higher resolution around the equator). There are $31 \mathrm{lev-}$ els both in the ocean and the atmosphere. The millennium simulation using this model is described in detail in Swingedouw et al. (2011). It uses most of the known external forcing (solar, volcanoes, $\mathrm{CO}_{2}$ ). The Total Solar Irradiance (TSI) variations are deduced from the Bard et al. (2000) reconstruction and we use the scaling from Crowley (2000). The amplitude of the solar forcing variations for the TSI reconstruction that we use represents a $0.24 \%$ decrease of the mean TSI between present day and the Maunder Minimum. While changes in solar forcing may concern the whole spectrum of solar irradiance (Gray et al., 2010), we do not account for this effect here. Other impacts, like the response of stratospheric ozone is also not accounted for and we only consider in the radiative forcing from the TSI. Moreover, there is a lot of debate concerning the magnitude of TSI changes in the past, with reconstructions considering smaller (Vieira et al., 2011) or larger (Shapiro et al., 2011) magnitude than the one used

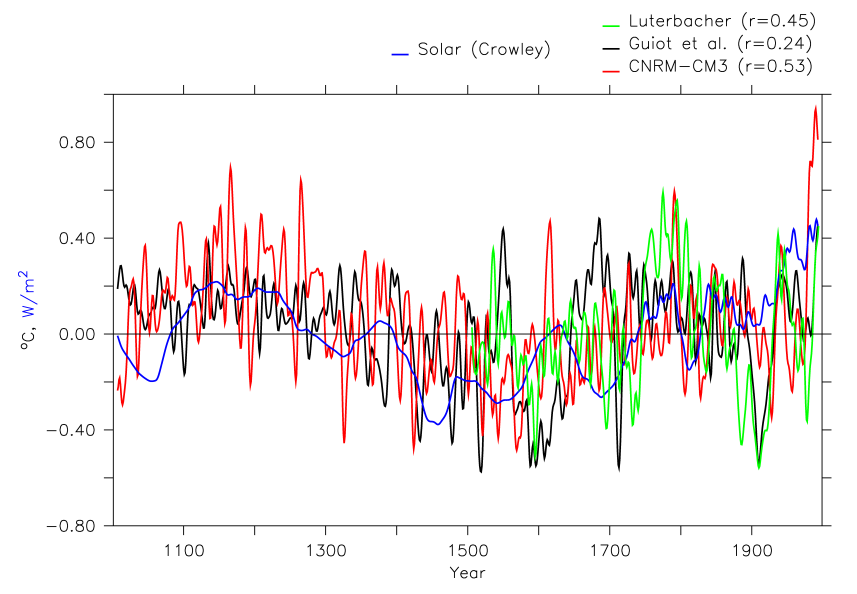

Fig. 1. Time series of the summer (April to September) European mean temperature (in ${ }^{\circ} \mathrm{C}$ ) filtered with a $13 \mathrm{yr}$ cutoff value. In black is the reconstruction from Guiot et al. (2010), in green is the reconstruction from Luterbacher et al. (2004) and in red is the simulation from the model CNRM-CM3. In blue the mean radiative forcing from solar variations (in $\mathrm{W} \mathrm{m}^{-2}$ ) is represented from Crowley (2000) with its own axis in blue on the left. The spatial average is computed over the region $10^{\circ} \mathrm{W}-60^{\circ} \mathrm{E}, 25^{\circ} \mathrm{N}-75^{\circ} \mathrm{N}$ in the Guiot et al. (2010) reconstruction and in the model and over a smaller region $\left(10^{\circ} \mathrm{W}-40^{\circ} \mathrm{E}, 35^{\circ} \mathrm{N}-70^{\circ} \mathrm{N}\right)$ for the Luterbacher et al. (2004) reconstruction.

here. The scaling used in this simulation can be considered as a large one.

This simulation correctly simulates the large-scale variations of the annual mean Northern Hemisphere temperature since it falls within the range of reconstructions at the hemispheric level (Swingedouw et al., 2011). This simulation also exhibits multidecadal variations for the North Atlantic Oscillation in winter and for the AMOC that are modulated by the forcings. While Swingedouw et al. (2011) focused on winterdelayed response to solar forcing, here we will concentrate on the response to solar forcing over Europe in summer and in phase with solar variations (lagged responses indeed produce lower statistical significance in summer over Europe in the simulation, not shown). For this purpose, we compare this simulation with the spatio-temporal reconstruction over Europe $\left(10^{\circ} \mathrm{W}-60^{\circ} \mathrm{E}, 25^{\circ} \mathrm{N}-75^{\circ} \mathrm{N}\right)$ for summer (April to September) temperature from Guiot et al. (2010), based on different proxies (mainly tree rings and pollen reconstructions) covering a large part of Europe.

To compare the fingerprint from solar forcing in the simulation with this reconstruction, we interpolate the summer data from the model onto the grid from Guiot et al. (2010) reconstruction. Then, we use regression analysis of the temperature for each point on the TSI variability (represented in Fig. 1). To minimise the climatic signature of the volcanoes and of the interannual variability, we apply a low pass Lanczos time-filter (Duchon, 1979) to all the fields analysed hereafter, with cut-off values of $13 \mathrm{yr}$. This technique does not 
allow filtering out the low frequency effect coming from the volcanoes (illustrated in Otterå et al., 2010) and detected for instance by Hegerl et al. (2007). Indeed, solar minima sometimes occur concomitantly with volcanic eruptions (Ammann et al., 2007) as for instance in the Dalton minimum and the Tambora eruption. Nevertheless, solar and volcanic forcings are not well correlated because they contain very different spectral features. Thus, we make the assumption that the proposed regression mainly captures the response of the low frequency coming from the solar forcing. This assumption remains a weakness of the present paper, but due to computation cost, we could not provide a simulation with only solar forcing using CNRM-CM3. In order to further evaluate this assumption, we have performed similar regressions to what is shown later but we have excluded the $11 \mathrm{yr}$ following eruptions larger than Pinatubo; we found very similar patterns (not shown). The statistical significance of the correlations and regressions computed in this study are estimated by using a "random-phase" test that accounts for the serial correlation effect due to the low-pass filtering of the reconstruction (Ebisuzaki, 1997).

\section{Results}

The evolution of summer temperature averaged over the whole Europe is represented in Fig. 1. For the period 10011860 , the standard deviation is $0.22^{\circ} \mathrm{C}$ in the reconstruction and $0.18^{\circ} \mathrm{C}$ in the model. The correlation between the two time series is only of 0.25 (statistically significant at the $95 \%$ level). Indeed the simulation misses high amplitude variations especially for the period between 1500-1700, but the main trend related to solar forcing (correlation of 0.24 between solar forcing and the temperature reconstruction and of 0.53 in the simulation) is simulated by the model. The correlation with solar forcing is higher when limited to the period 1100-1500 (a period not considered in the Hegerl et al., 2011 analysis) and reaches the same value of 0.56 both in the model and the reconstruction. As an additional test, we use the Luterbacher et al. (2004) reconstruction for Europe over the period $1500-1860$. We find a better correlation of 0.45 (significant at the $95 \%$ level) with solar forcing over this time period. In particular we notice that the large disagreement between model and Guiot et al. (2010) reconstruction over the period $1500-1700$ is lower in the Luterbacher et al. (2004) reconstruction. The two reconstructions are not consistent over this time period, which questions the very strong variations occurring on this time frame in the Guiot et al. (2010) reconstruction, which are not reproduced in the model. Moreover, it should be stressed that the correlation with solar forcing is better in the simulation than in both reconstructions. This could be related to the fact that the solar forcing used in the model is perfectly known while the real one still remains under debate (Gray et al., 2010). a) Guiot et al.

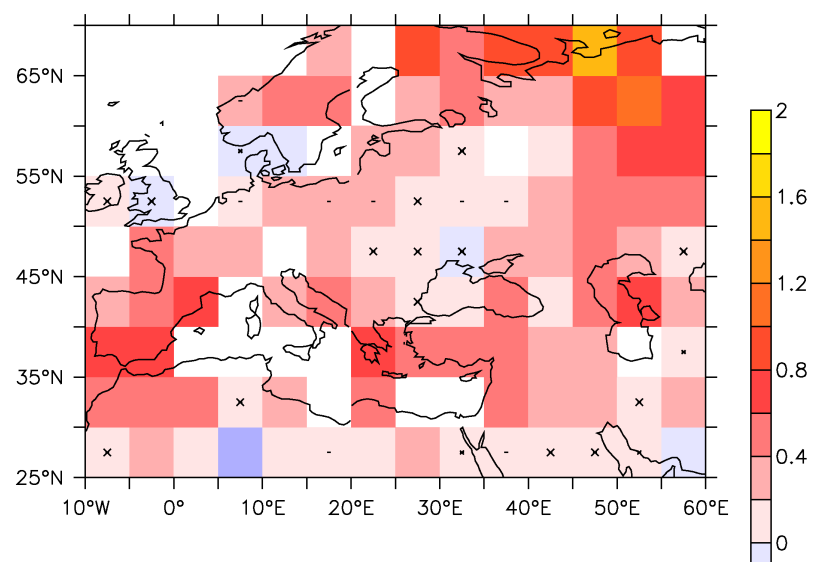

b) $\mathrm{CNRM}-\mathrm{CM} 3$

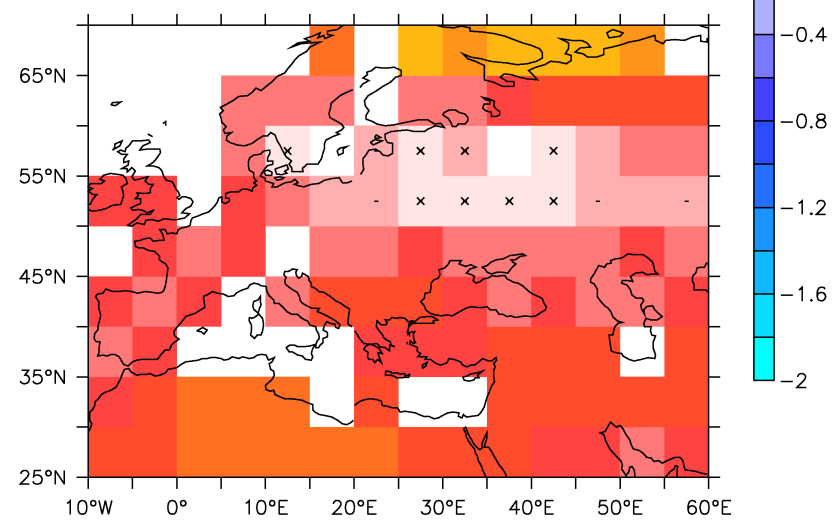

Fig. 2. (a) Spatial regression of the summer temperature from Guiot et al. (2010) on the solar variations (in ${ }^{\circ} \mathrm{C} / \mathrm{W} \mathrm{m}^{-2}$ ) for the period 1001-1860. The large black crosses indicate the point not significant at $90 \%$, the smaller one, the region not significant at $95 \%$ and the horizontal line at the $99 \%$ level. (b) same as (a) but for the simulation (note that the ocean point have been excluded since the data used by Guiot et al., 2010 are from land).

Figure 2 shows the spatial temperature regression over the solar forcing in the reconstruction and the model for zero time lags. We notice that for most of the grid points the regression is positive and statistically significant at the $90 \%$ level. This means that the surface temperature increases with an increase in solar forcing, in agreement with the associated changes in radiative forcing at the top of the atmosphere (Fig. 3a). The solar forcing is related with short wave variation at the top of the atmosphere. This forcing is almost isotropic over Europe as shown in Fig. 3a only with slight decrease of the forcing in latitude related with the rotundity of the Earth ( $26 \%$ lower at $75^{\circ} \mathrm{N}$ than at $25^{\circ} \mathrm{N}$, cf. Fig. 3a). Nevertheless, the response to this radiative forcing changes exhibit a complex spatial response, with a large warming in the north and south of Europe and a lesser warming in the centre, both in the reconstruction and in the model. The latitudinal agreement is actually quantitatively correct as shown 
a) Downward SW TOA

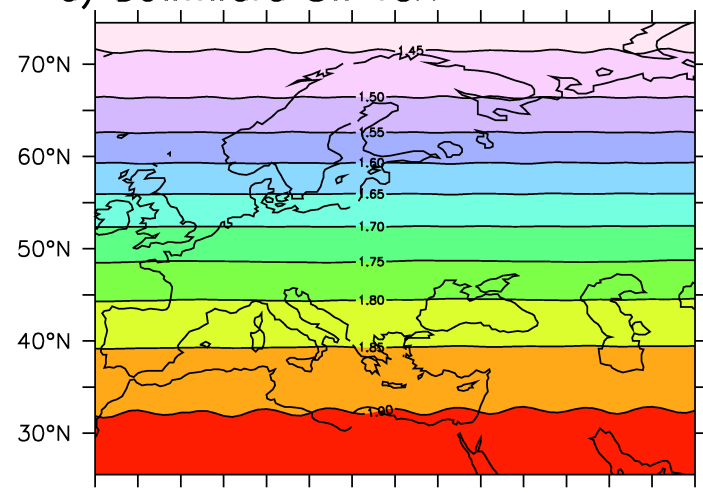

c) Precip.

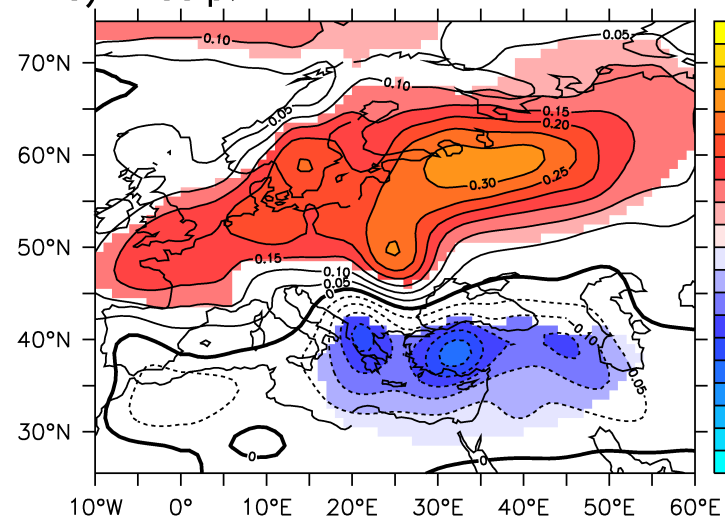

b) Cloud
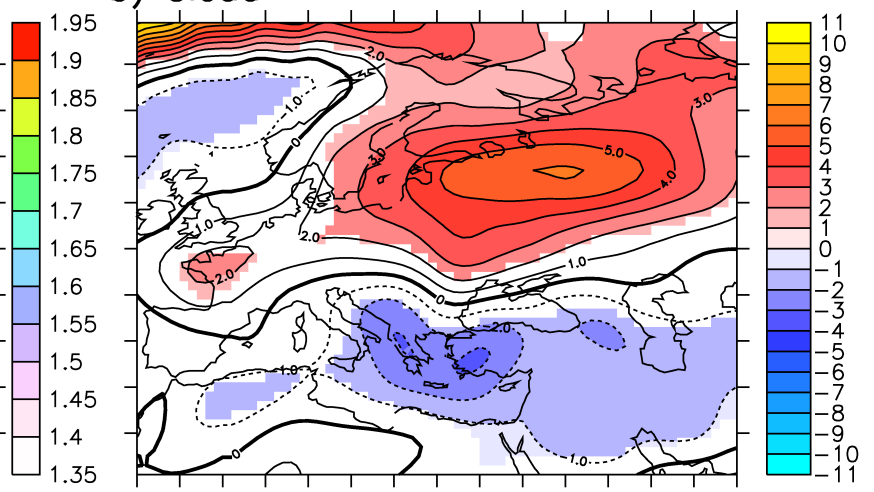

d) Evapotranspiration
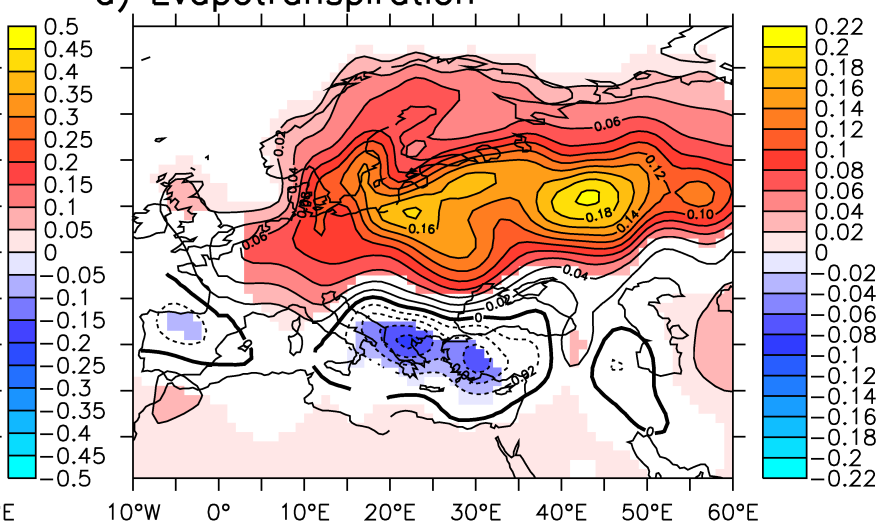

Fig. 3. Regression of different variables from the model simulation on the solar variations for the period 1001-1860. (a) Downward shortwave (SW) radiation at the top of the atmosphere (TOA) in $\mathrm{W} \mathrm{m}^{-2} / \mathrm{W} \mathrm{m}^{-2}$. (b) Cloud concentration in $\% / \mathrm{W} \mathrm{m}^{-2}$. (c) Precipitation in $\mathrm{mm} \mathrm{day}^{-1} / \mathrm{W} \mathrm{m}^{-2}$. (d) Evapotranspiration in $\mathrm{mm} \mathrm{day}^{-1} / \mathrm{W} \mathrm{m}^{-2}$. The sign is positive for cloud, precipitation, evapotranspiration and downward SW when the variables increase with solar forcing. The shaded regions represent regions with statistically significant regression value at the $95 \%$ level.

in Fig. 4: there is a similar minimum of warming around $55^{\circ} \mathrm{N}$ with an increased warming north of it, sharing a similar increase, although largely overestimated after $65^{\circ} \mathrm{N}$ in the model as compared to the reconstruction. South of the $55^{\circ} \mathrm{N}$ minimum, the regressed temperature also increases but south of $40^{\circ} \mathrm{N}$, the increase in the model becomes more than two times larger than in the reconstruction. The signature of solar forcing over Central and Eastern Europe is not significant in a lot of grid-points from the model and the reconstruction (Fig. 2). Given that the solar forcing is almost isotropic over Europe, the latitudinal temperature response found in Fig. 4 remains remarkable and is certainly the results of local feedback or change in large-scale circulation, which needs to be explained. For that purpose we analyse the response of the model to solar forcing variations.

We notice in the model (Fig. 3) an increase in cloud cover, precipitation and evapotranspiration over Central and Eastern Europe related to the increase in solar forcing. For these variables, Central and Eastern Europe are the regions that exhibit the largest changes, which is surprising given the small temperature response. We argue that this response of

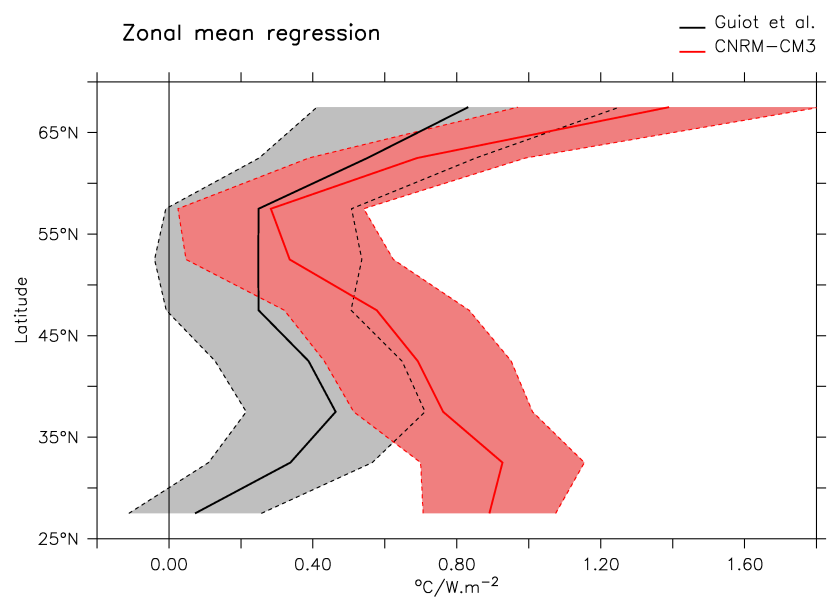

Fig. 4. Regression of the zonal mean summer temperature over the solar forcing, in black for the reconstruction and in red for the simulation. The dashed lines correspond to a two standard deviation error bar computed from the residual of the regression. 


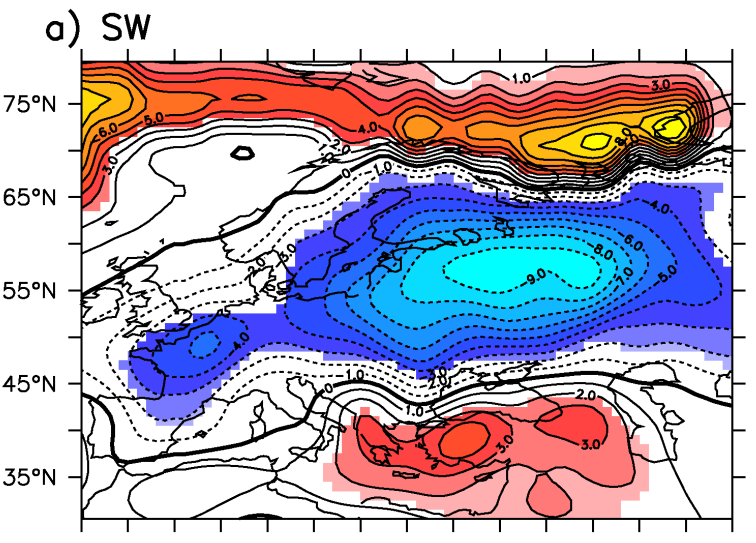

c) Sensible

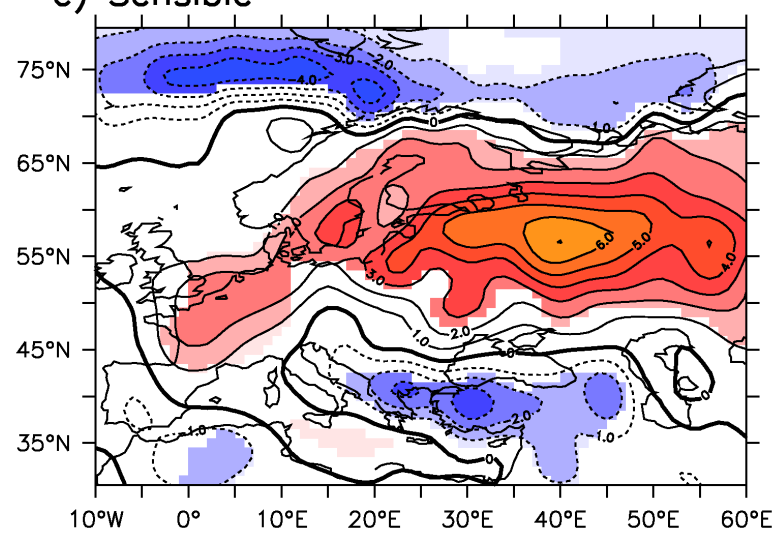

b) LW

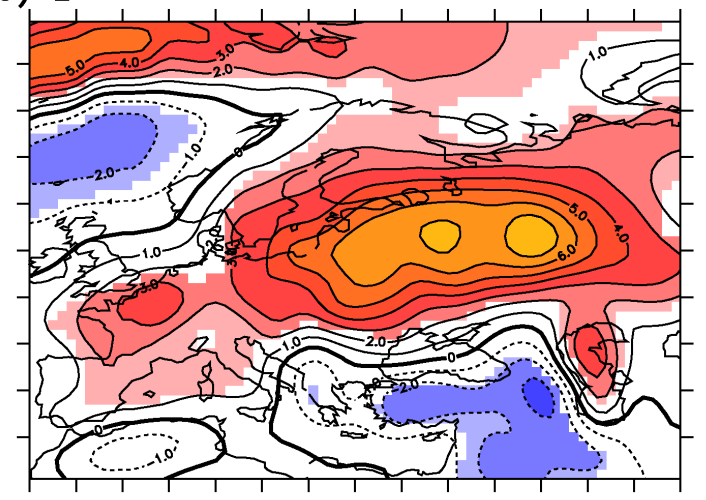

d) Latent

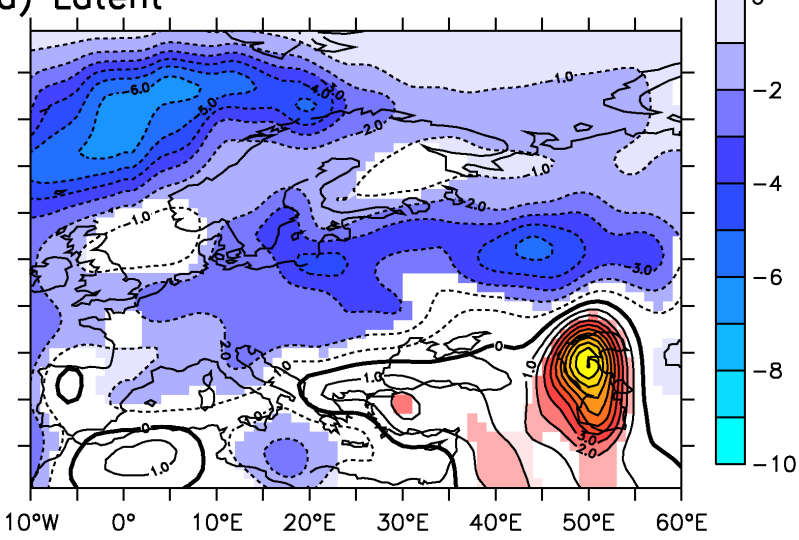

Fig. 5. Same as Fig. 3 but for (a) the net shortwave radiation at the surface, (b) the net longwave radiation at the surface, (c) the sensible heat flux, (d) the latent heat flux. All panels are expressed in $\mathrm{W} \mathrm{m}^{-2} / \mathrm{W} \mathrm{m}^{-2}$.

evapotranspiration and clouds may indeed explain the minimum warming found around $55^{\circ} \mathrm{N}$ in the model because of a damping of the forcing effect on surface temperature. Over the Mediterranean area the opposite signal is found.

We propose that the changes in evapotranspiration are the explanation for the temperature response found. Following the mechanism proposed by Schär et al. (1999, see their Fig. 1) an increase in evapotranspiration in summer leads to convective clouds that may interact with the large-scale circulation. In the simulation we actually find that the increase in precipitation in the region $10^{\circ} \mathrm{E}-50^{\circ} \mathrm{W}, 45-65^{\circ} \mathrm{N}$ is $0.20 \mathrm{~mm} / \mathrm{W} \mathrm{m}^{-2}$, and we diagnose that $65 \%$ of this increase is related to convective precipitations (diagnostic computed in the model). This is similar to the Schär et al. (1999) mechanism: in response to an increase in evapotranspiration, there is an interaction between the convective cell with the main circulation, which increases the precipitation in this region, in addition to the recycling from the evaporative water from the soil. This change in cloud cover impacts the radiative budget over this region (Fig. 5) with less shortwave radiation at the surface and more longwave radiation and sensible heat fluxes, while the absolute latent heat flux increase accordingly with the evapotranspiration fluxes. The minimum warming over Central and Eastern Europe results from this surface heat fluxes changes, dominated by a decrease in shortwave fluxes. Over the Mediterranean area, the decrease in evapotranspiration (Fig. 5c) is associated with the drying of the soil (and the lack of soil moisture availability to increase this flux). Such a different behaviour between Central and Eastern Europe and Mediterranean area can be compared to the two stable states found in D'Andréa et al. (2006): depending on the soil moisture initial condition at the beginning of the summer, two very different states can take place.

The increase in evapotranspiration in Central and Eastern Europe is actually related to a larger availability of soil moisture at the beginning of summer. This is what is shown in Fig. 6: in summer both in the model and in a reanalysis (Alkama et al., 2010), the evapotranspiration is controlled through moisture (rather than radiative flux, e.g. Severinatne and Stockli, 2008, their Fig. 3). The increase in evapotranspiration in summer is therefore related to an increase in soil moisture at the beginning of the summer, followed by the soil-precipitation feedback from Schär et al. (1999). To explain this increase in soil moisture, we find an increase in precipitation in winter when regressed over the solar index over Central and Eastern Europe (not shown). This increase 


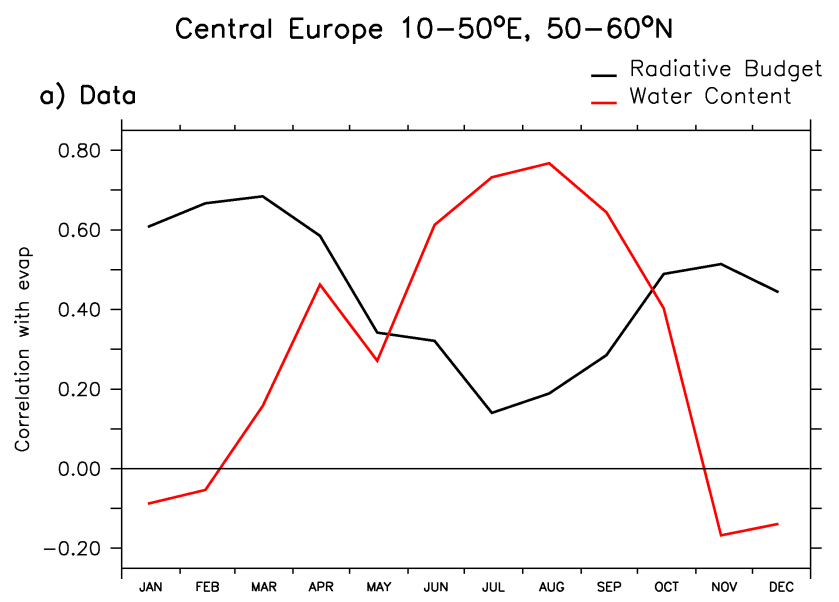

b) Model

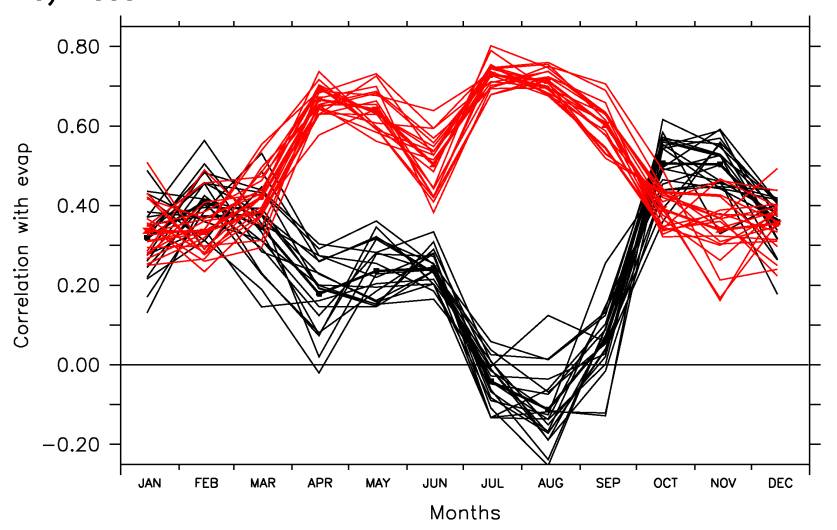

Fig. 6. Correlation between the net radiative forcing and evapotranspiration (in black) and soil water content and evapotranspiration (in red) for a region of Central and Eastern Europe (10-50 E, 50$60^{\circ} \mathrm{N}$ ) for different months (on the X-axis) (a) in a reanalysis from Alkama et al. (2010) over the period 1950-2000 and (b) in the model simulation, the period 1001-1800. The different lines in (b) correspond to a computation every $50 \mathrm{yr}$ starting from 1001-1050 (until 1800-1850). This has been done in order to evaluate the stationarity of the relationship in the model.

may allow increasing the loading of soil moisture in winter and spring and leads to the mechanism proposed. This increase in precipitation in winter is not related to a change in large-scale circulation (no significant correlation found with weather regimes frequency or empirical orthogonal function of the sea-level pressure over the North Atlantic region, not shown) but could be explained by the Clausius-Clapeyron relationship, since the temperature is enhanced in winter in response to the increase in solar forcing (Swingedouw et al., 2011, their Fig. 3a). The whole mechanism for Central and Eastern Europe is summarized in Fig. 7.

For the Mediterranean area, this effect is not sufficient, so that the soil becomes dry leading to the large warming observed in the model, which seems overestimated as compared to the reconstruction. Changes in large-scale circulation and

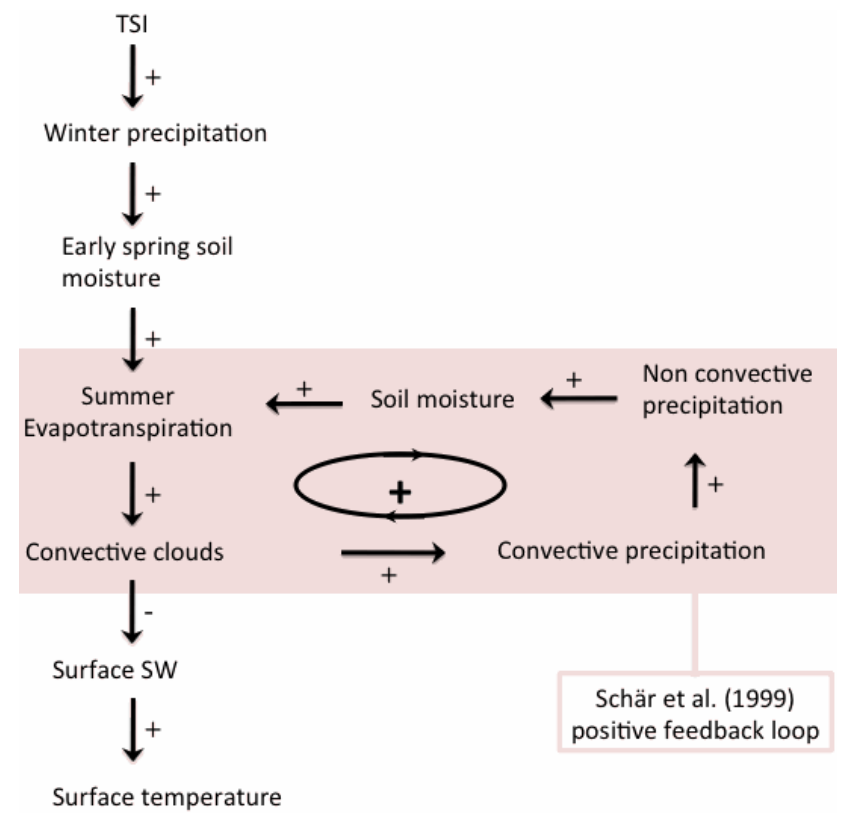

Fig. 7. Scheme of the proposed mechanism operating in Central and Eastern Europe. The sign between the two variables at each side of any arrow explains the relationship between them ("+" for increase and "-" for decrease). The Schär et al. (1999) positive feedback loop has been highlighted in light pink.

the subsidence zone have been argued to play a crucial role in future climatic projections for the drying of the Mediterranean area (Yin, 2005). Here we do not find any clear signature of a change in the main circulation patterns (Fig. 8b) so that we believe that it is mainly local feedbacks that are playing a role in our simulation. This may be related to the relatively weak forcing of the solar variations as compared to what happens in most projections.

In the North, the evapotranspiration is not controlled by soil moisture but rather by the (low) radiative flux availability so that the former mechanism does not apply (Seneviratne and Stöckli, 2008). The large warming found in this region can be explained by the sea-ice retreat as shown in Fig. 8a. Indeed in summer we find a decrease of $1.52 \times 10^{11} \mathrm{~m}^{2} / \mathrm{W} \mathrm{m}^{-2}$ of sea-ice cover in the Nordic and Barents Seas when the solar forcing increases. This sea-ice retreat leads through albedo feedback to a larger net short wave at the surface (Fig. 5a) amplifying the warming there. Its effect on the large-scale circulation is not significant (Fig. 8b), so that we argue that it is mainly a local feedback process that explains the warming in the North. A reconstruction of sea-ice variations north of Iceland over the last millennium (Massé et al., 2008) indeed show large variations of the sea-ice cover in this location, notably with a maximum over the last millennium around 1690, which corresponds to the Maunder solar minimum without any large volcanic eruption at that time. 
a) Sea-ice cover

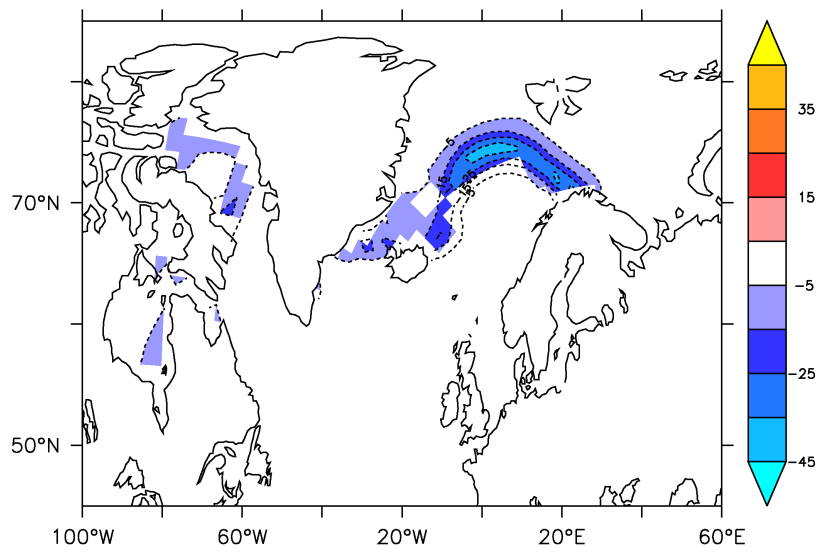

b) Sea-level pressure

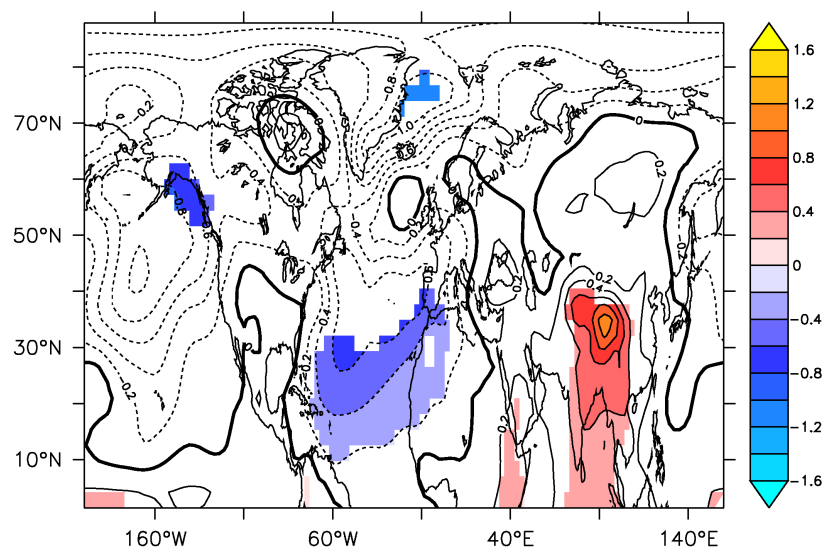

Fig. 8. Similar to Fig. 3 but for (a) sea-ice cover (in $\% / \mathrm{W} \mathrm{m}^{-2}$ ) and (b) sea-level pressure (in $\mathrm{hPa} / \mathrm{W} \mathrm{m}^{-2}$ ). The significant regions at the $95 \%$ level are shaded in color.

\section{Conclusions}

In this study, we have shown that over the preindustrial period of the last millennium, a regression of surface temperature in summer over solar forcing in the CNRM-CM3 model and the Guiot et al. (2010) reconstruction shares a similar latitudinal pattern in Europe with a minimum response around $55^{\circ} \mathrm{N}$. To explain the qualitatively correct representation of the temperature latitudinal response to solar forcing at low frequency in the model as compared to the reconstruction, we argue that the evapotranspiration changes as well as their interactions with atmosphere (convection, radiative adjustment with cloud) are the leading processes.

This study therefore shows that spatio-temporal temperature reconstruction can be useful to evaluate simulated low frequency variability. A time scale long enough such as the last millennium allows increasing the signal-to-noise ratio of the radiative forcing on the climate. The latitudinal agreement between model and observed reconstruction is correct except for latitude larger than $65^{\circ} \mathrm{N}$ and around the Mediterranean area, where warming is overestimated in the model.
This difference can be due to an incorrect representation of the soil processes in the model. There are also large uncertainties for the scaling used for solar forcing, which can explain the difference. Indeed a lower solar forcing may induce lower response in the model, more in agreement with the reconstruction. Moreover, there are fewer data over the Mediterranean area in the Guiot et al. (2010) reconstruction, which may increase the uncertainty over this area. Reconstruction and model show a similar minimum around $55^{\circ} \mathrm{N}$, but the model misses another local minimum in the reconstruction located around $45^{\circ} \mathrm{N}$. This disagreement could indicate that the transition zone defined by Boé and Terray (2008) is too far to the north in the model as compared to the one we found in the reconstruction. This result may suggest a deficiency in the response that implies that caution has to be exercised when considering projections over this region with this model.

We would like to make some caveats concerning this study. First of all, the correlation between the reconstruction and solar forcing remains small when averaged over Europe, in agreement with Hegerl et al. (2011). Nevertheless we argue here, that this is notably because the signal over Central and Eastern Europe is considerably damped, implying very small correlation with solar forcing. The extension of our time frame to the period before 1500 (as compared to Hegerl et al., 2011) also improves the correlation we find with solar forcing. Moreover, it will be very useful to extend the present analysis to other climate models in order to evaluate if they found a similar large evapotranspiration response to solar forcing in summer as in the CNRM-CM3 and a similar latitudinal response and minimum. Finally, we have compared the correlation of a few others summer reconstructions with solar forcing and found no significant correlation with data from Central Europe (Büntgen et al., 2011) or in the Pyrenees (Büntgen et al., 2008) for the last millennium. A recent Fennoscandia reconstruction also does not exhibit large coherence with solar forcing (D. McCarroll, personal communication, 2012) as well as a former one (Lindholm et al., 2011), so that the slight correlation found in this study is not consistent with a few local reconstructions. The results from the data side therefore need to be taken with cautious. Nevertheless, we propose that the inclusion of pollen data in the Guiot et al. (2010) reconstruction may improve the low frequency representation of the variability and therefore the correlation with the solar forcing as compared to reconstructions only based on tree ring. The correlation with solar and associated mechanism found in the model appears more clearly. This could indicate that the solar forcing chosen in this model is stronger than what it may have been in reality, agreeing with Foukal et al. (2006). Indeed, the amplitude of the solar reconstructions we use can be considered as large as compared to others recent reconstruction with a lower scaling (Gray et al., 2010).

Finally, we conclude that it is useful to continue the improvement of spatio-temporal reconstruction of the last 
millennium, and to simulate this long period with climate models in order to evaluate the processes explaining the response to change in radiative forcing such as the solar one.

Acknowledgements. We thank Ramdane Alkama for providing the data of the soil moisture and evapotranspiration over Europe. This paper is a contribution to the project ESCARSEL funded by the French Agency for National Research (ANR VMC 2006). The use of the software packages statpack, safo and ferret is acknowledged.

Edited by: V. Rath

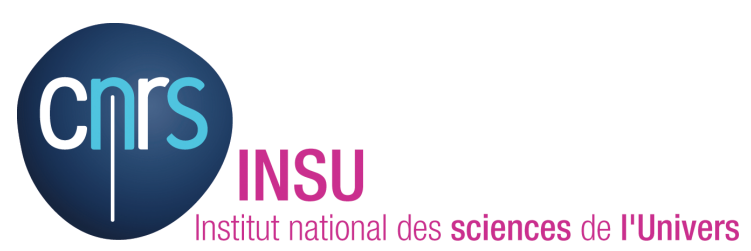

The publication of this article is financed by CNRS-INSU.

\section{References}

Alkama, R., Decharme, B., Douville, H., Becker, M., Cazenave, A., Sheffield, J., Voldoire, A., Tyteca, S., and Le Moigne, P.: Global evaluation of the ISBA-TRIP continental hydrological system, Part I: Comparison to GRACE terrestrial water storage estimates and in situ river discharges, J. Hydrometeorol., 11, 583-600, 2010.

Ammann, C. M., Joos, F., Schimel, D., Otto-Bliesner, B. L., and Tomas, R.: Solar influence on climate during the past millennium: results from transient simulations with the NCAR Climate System Model, P. Natl. Acad. Sci., 104, 3713-3718, 2007.

Bard, E., Raisbeck, G., Yiou, F., and Jouzel, J.: Solar irradiance during the last 1200 years based on cosmogenic nuclides, Tellus B, 50, 985-992, 2000.

Boé, J. and Terray, L.: Uncertainties in summer evapotranspiration changes over Europe and implications for regional climate change, Geophys. Res. Lett., 35, L05702, doi:10.1029/2007GL032417, 2008.

Büntgen, U., Frank, D. C., Grudd, H., and Esper, J.: Long-term summer temperature variations in the Pyrenees, Clim. Dynam., 31, 615-631, 2008.

Büntgen, U., Tegel, W., Nicolussi, K., McCormick, M., Frank, D., Trouet, V., Kaplan, J., Herzig, F., Heussner, U., Wanner, H., Luterbacher, J., and Esper, J.: 2500 years of European climate variability and human susceptibility, Science, 331, 578$582,2011$.

Christensen, J. H., Hewitson, B., Busuioc, A., Chen, A., Gao, X., Held, I., Jones, R., Kolli, R. K., Kwon, W.-T., Laprise, R., Magana Rueda, V., Mearns, L., Mennendez, C. G., Raisanen, J., Rinke, A., Sarr, A., and Whetton, P.: Regional climate projections, in: Climate Change 2007: The Physical Science Basis. Contribution of Working Group I to the Fourth Assessment Report of the Intergovernmental Panel on Climate Change, edited by: Solomon, S., Qin, D., Manning, M., Chen, Z., Marquis, M.,
Averyt, K. B., Tignor, M., and Miller, H. L., Cambridge University Press, Cambridge, New York, 2007.

Crowley, T. J.: Causes of climate change over the past 1000 years, Science, 289, 270-277, 2000.

D’Andréa, F., Provenzale, A., Vautard, R., and DeNobletDucoudré, N.: Hot and cool summers: multiple equilibria of the continental water cycle, Geophys. Res. Lett., 33, L24807, doi:10.1029/2006GL027972, 2006.

Duchon, C. E.: Lanczos filtering in one and two dimensions, J. Appl. Meteorol., 18, 1016-1022, 1979.

Ebisuzaki, W.: A method to estimate the statistical significance of a correlation when the data are serially correlated, J. Climate, 10, 2147-2153, 1997.

Foukal, P., Fröhlich, C., Spruit, H., and Wigley, T. M. L.: Variations in solar luminosity and their effect on the Earth's climate, Nature, 443, 161-166, doi:10.1038/nature05072, 2006.

Gibelin, A. L. and Déqué, M.: Anthropogenic climate change over the Mediterranean region simulated by a global variable resolution model, Clim. Dynam., 20, 327-339, 2003

Gray, L. J., Beer, J., Geller, M., Haigh, J. D., Lockwood, M., Matthes, K., Cubasch, U., Fleitmann, D., Harrison, G., Hood, L., Luterbacher, J., Meehl, G. A., Shindell, D., van Geel, B., and White, W.: Solar influence on climate, Rev. Geophys., 48, RG4001, doi:10.1029/2009RG000282, 2010.

Guiot, J., Corona, C., and ESCARSEL members: Growing season temperatures in Europe and climate forcings over the past 1400 years, PLoS ONE, 5, e9972, doi:10.1371/journal.pone.0009972, 2010.

Hegerl, G. C., Crowley, T., Allen, M., Hyde, W. T., Pollack, H., Smerdon, J., and Zorita, E.: Detection of human influence on a new 1500 yr climate reconstruction, J. Climate, 20, 650-666, 2007.

Hegerl, G., Luterbacher, J., González-Rouco, F., Tett, S. F. B., Crowley, T., and Xoplaki, E.: Influence of human and natural forcing on European seasonal temperatures, Nat. Geosci., 3, 688-694, 2011.

Hunt, B. G.: The Medieval Warm Period, the Little Ice Age and simulated climatic variability, Clim. Dynam., 27, 677-694, 2006.

Lindholm, M., Jalkanen, R., Salminen, H., Aalto, T., and Ogurtsov, M.: The height-increment record of summer temperature extended over the last Millennium in Fennoscandia, Holocene, 21, 319-326, doi:10.1177/0959683610378875, 2011.

Luterbacher, J., Dietrich, D., Xoplaki, E., Grosjean, M., and Wanner, H.: European seasonal and annual temperature variability, trends, and extremes since 1500, Science, 303, 1499-1503, 2004.

Madec, G., Delecluse, P., Imbard, M., and Lévy, C.: OPA version 8, Ocean general circulation model reference manual, Rapp. Int., LODYC, France, p. 200, 1998.

Massé, G., Rowland, S. J., Sicre, M.-A., Jacob, J., Jansen, E., and Belt, S. T.: Abrupt climate changes for Iceland during the last millennium: Evidence from high resolution sea ice reconstructions, Earth Planet. Sc. Lett., 269, 564-568, doi:10.1016/j.epsl.2008.03.017, 2008.

Otterå, O. H., Bentsen, M., Drange, H., and Suo, L.: External forcing as a metronome for Atlantic multidecadal variability, Nat. Geosci., 4, 99-103, 2010.

Salas-Mélia, D.: A global coupled sea ice-ocean model, Ocean Model., 4, 137-172, 2002. 
Salas-Mélia, D., Chauvin, F., Déqué, M., Douville, H., Gueremy, J. F., Marquet, P., Planton, S., Royer, J. F., and Tyteca, S.: Description and validation of the CNRM-CM3 global coupled model, CNRM technical report 103, http://www.cnrm.meteo.fr/ scenario2004/paper_cm3.pdf, available from CNRM/GMGEC, Toulouse, France, 2005.

Scaife, A. A., Spangehl, T., Fereday, D. R., Cubasch, U., Langematz, U., Akiyoshi, H., Bekki, S., Braesicke, P., Butchart, N., Chipperfield, M. P., Gettelman, A., Hardiman, S. C., Michou, M., Rozanov, E., and Shepherd, T. G.: Climate change projections and stratosphere-troposphere Interaction, Clim. Dynam., 38, 2089-2097, doi:10.1007/s00382-011-1080-7, 2012.

Schär, C., Luthi, D., Beyerle, U., and Heise, E.: The soilprecipitation feedback: a process study with a regional climate model, J. Climate, 12, 722-741, 1999.

Seneviratne, S. I. and Stöckli, R.: The role of land-atmosphere interactions for climate variability in Europe, in: Climate Variability and Extremes during the Past 100 years, in: Adv. Global Change Res., edited by: Brönnimann, S., Luterbacher, J., Ewen, T., Diaz, H. F., Stolarski, R. S., and Neu, U., 33, Springer Verlag, 2008.
Seneviratne, S. I., Luthi, D., Litschi, M., and Schär, C.: Landatmosphere coupling and climate change in Europe, Nature, 443, 205-209, 2006.

Shapiro, A. I., Schmutz, W., Rozanov, E., Schoell, M., Haberreiter, M., Shapiro, A. V., and Nyeki, S.: A new approach to the long-term reconstruction of the solar irradiance leads to large historical solar forcing, Astron. Astrophys., 529, A67, doi:10.1051/0004-6361/201016173, 2011.

Swingedouw, D., Terray, L., Cassou, C., Voldoire, A., Salas-Mélia, D., and Servonnat, J.: Natural forcing of climate during the last millennium: fingerprint of solar variability, Clim. Dynam., 36, 1349-1364, 2011.

Vieira, L. E. A., Solanki, S. K., Krivova, N. A., and Usoskin, I.: Evolution of the solar irradiance during the Holocene, Astron. Astroph., 531, A6, doi:10.1051/0004-6361/201015843, 2011.

Yin, J. H.: A consistent poleward shift of the storm tracks in simulations of 21st century climate, Geophys. Res. Lett., 32, L18701, doi:10.1029/2005GL023684, 2005. 